\title{
O COMITÊ INTERNACIONAL DA CRUZ VERMELHA COMO AGENTE MATERIALIZADOR DO DIREITO INTERNACIONAL HUMANITÁRIO
}

\author{
Elder Maia Goltzman ${ }^{1}$ \\ Mônica Teresa Costa Sousa ${ }^{2}$
}

\section{RESUMO}

O Direito Internacional Humanitário (DIH) é compreendido como um ramo do Direito Internacional Público que visa proteger as vítimas de conflitos armados. Esta pesquisa, realizada com base no método analítico-descritivo e baseada em análise bibliográfica, busca investigar qual a relação existente entre o DIH e o Comitê Internacional da Cruz Vermelha (CICV), historicamente vinculado ao DIH. Traçam-se como objetivos a análise do surgimento do Comitê, de seus princípios norteadores e de seu campo de atuação prática. Dentre a bibliografia levantada, priorizam-se as publicações oriundas do próprio CICV por sua relevância e especificidade.

Palavras-chave: Direito Internacional Humanitário; Comitê Internacional da Cruz Vermelha; Agente Materializador; Princípios

\section{THE INTERNATIONAL COMMITTEE OF THE RED CROSS AS THE MATERIALIZING AGENT OF INTERNATIONAL HUMANITARIAN LAW}

\begin{abstract}
International Humanitarian Law (IHL) is understood as a branch of Public International Law that aims to protect victims of armed conflicts. This research, carried out based on the analytical-descriptive method and based on bibliographic analysis, seeks to investigate the relationship between IHL and the International Committee of the Red Cross (CRC), historically associated to the IHL. The main objectives are to analyze the emergence of the Committee, its guiding principles and its field of practical action. Among the bibliography surveyed, publications from the ICRC itself are prioritized for their relevance and specificity.
\end{abstract}

Keywords: International Humanitarian Law; International Committee of the Red Cross; Materializing Agent; Principles

\section{INTRODUÇÃO}

O Direito Internacional Humanitário (DIH) é compreendido como um ramo do Direito Internacional Público que, fazendo parte do sistema internacional de proteção dos direitos humanos, salvaguarda os indivíduos que são vítimas de confrontos armados. Sabe-se que

1 Mestrando em Direito e Instituições do Sistema de Justiça na UFMA. Pós-graduado em Direito Administrativo. Analista Judiciário - Área Judiciária do TRE-PA. Email: eldergoltzman89@gmail.com

2 Doutora e Mestre em Direito pela Universidade Federal de Santa Catarina. Professora do Mestrado em Direito e Instituições do Sistema e Justiça e do Mestrado em Cultura e Sociedade, ambos na UFMA. Email: monica.teresa@ufma.br 
durante a condução das hostilidades há necessidade de cuidados médicos, alimento, remédio, água, abrigo e proteção, não só para os militares envolvidos no confronto direto, mas também para a população civil que se vê desprotegida.

Desponta como principal organismo internacional vinculado ao DIH o Comitê Internacional da Cruz Vermelha (CICV) que tem sua sede localizada em Genebra, Suíça. O CICV tem alcance global com suas filiais espalhadas pelos diversos cantos do planeta. Contudo, percebe-se que o CICV tem caracteres especiais que o distingue dos demais órgãos de ajuda humanitária.

Partido dessa percepção, esta pesquisa visa averiguar qual a ligação existente entre o Comitê Internacional da Cruz Vermelha e o Direito Internacional Humanitário. Objetiva discorrer, em especial, sobre a gênese do Comitê, assim como seus princípios norteadores e seu campo de atuação.

Para tanto, adota-se o método descritivo-analítico em que se levanta a literatura existente e, em seguida, disserta-se sobre a temática através de uma lente crítica. A investigação adota como técnica de pesquisa a bibliográfica, mormente os textos produzidos pelo próprio Comitê Internacional da Cruz Vermelha.

O texto foi construído e dividido em três partes. Primeiro, estuda-se o surgimento do CICV e suas contribuições para o Direito Internacional Humanitário ao longo da história, com destaque para as guerras mundiais. Posteriormente, analisam-se os princípios que guiam a conduta da organização e que estão relacionados com os próprios princípios do DIH. A terceira e derradeira parte trata especificamente do campo de atuação do CICV enquanto agente materializador do DIH.

\section{A CODIFIÇÃo DO DIREITO HUMINTÁRIO E A CRIAÇÃo DA CRUZ VERMELHA: UMA SIMBIOSE}

Didaticamente, o próprio $\mathrm{CICV}$, no sítio oficial, divide seu histórico em cinco períodos principais: a fundação (1863-1914), a Primeira Guerra Mundial, os anos de 1918 a 1939, a Segunda Guerra mundial e o lapso que compreende de 1945 (fim da Segunda Grande Guerra) até os dias atuais ${ }^{3}$.

3 Registre-se que para os fins deste trabalho, no que tange à história do CICV, diversas fontes doutrinárias foram analisadas, notadamente Krieger (2004), Sousa, (2007) e Bouvier, Quintin e Sassòli (2011). Contudo, por 
A gênese do Comitê se deu com a Batalha de Solferino em 1859. Antes disso, "ainda que houvesse um ramo do Direito Internacional que estabelecesse as leis de guerra e os instantes de combate, não havia sequer em nível regional uma organização que atendesse as vítimas de guerra" (SOUSA, 2007, p. 126).

O confronto de Solferino, cidade localizada no norte da Itália, pôs de um lado as tropas francesas e sardenhas, comandadas pelo Imperador Napoleão III, e do outro lado, tropas austríacas. A guerra ocorreu em meio ao movimento de unificação italiana e deixou um saldo de nove mil feridos, além de mais de seis mil mortos. O enfrentamento teve início às três horas da madrugada do dia 24 de junho de 1854. Ao surgir o sol, 300 mil soldados se enfrentavam, atirando, pisando e cortando a garganta dos inimigos (INTERNATIONAL COMMITTEE OF THE RED CROSS, 2020).

Os serviços médicos da Sardenha e da França não podiam suportar a grande demanda de feridos e mutilados. Segundo o Comitê, o transporte dos enfermos era praticamente não existente, ao passo que comida e águas, escassos. A situação era caótica e o grau de violência desta guerra entrou para os anais da história europeia (INTERNATIONAL COMMITTEE OF THE RED CROSS, 2020).

Ocorre que, coincidentemente, por razões de negócios, encontrava-se naquela localidade o jovem suíço Henry Dunant que, observando a magnitude do conflito, reuniu diversas mulheres voluntárias da região e trabalhou para cuidar dos feridos e dos soldados à beira da morte, abandonados no campo de batalha. Para o suíço, todos os feridos deveriam ser tratados isonomicamente, independente do lado em que estavam na guerra (INTERNATIONAL COMMITTEE OF THE RED CROSS, 2020).

Ao retornar a seu país de origem, o empresário escreveu um livro, A Souvenier of Solferino, publicado no ano de 1862. Em sua obra, Dunant relatou "detalhadamente o desenvolvimento da batalha, as atrocidades por ele testemunhadas e a mobilização dos habitantes daquela região no atendimento aos enfermos” (KRIEGER, 2004, p.101).

Ressalte-se que o texto de Dunant não era apenas um memorial descritivo do conflito, mas também um guia com sugestões práticas de como ajudar aqueles indivíduos abandonados à própria sorte no campo de batalha.

Estou certo que uma vez que as pessoas comecem a pensar em um problema de tamanho interesse coletivo, como esse, tal atitude levará a reflexões e escritos de

acreditar que as informações partindo do próprio Comitê são dotadas de mais acurácia, optou-se por utilizar o sítio oficial da Cruz Vermelha (www.icrc.org) como principal fonte. 
pessoas mais capazes e competentes que eu. Até que isso ocorra, não está claro que para atingir esse nobre objetivo, a primeira necessidade é apresentar esta ideia aos diferentes ramos da família europeia, e que esta família assegure atenção e simpatia de todas as almas nobres, de todos os corações que podem ser movidos pelo sofrimento de seus semelhantes? Sociedades deste tipo, uma vez formadas e com sua existência permanente assegurada, naturalmente ficariam inativas em tempos de paz, mas estariam sempre organizadas e prontas diante da possibilidade de uma guerra (DUNANT, 1986, p. 30, traduziu-se.)

A Souvenier of Solferino repercutiu não somente junto à população suíça, mas também em outros países da Europa, tendo sido traduzida para quase todos os idiomas do continente e influenciado mentes importantes e de prestígio da época (SOUSA, 2007).

Assim, em fevereiro de 1863, a pedido de Gustave Moyner, presidente da Sociedade para o Bem-Estar Público de Genebra (Geneva Public Welfare Society), entidade de fins filantrópicos, um Comitê de cinco cidadãos suíços foi convocado com a finalidade de estudar as propostas de Dunant e sua viabilidade, objetivando torná-las uma realidade (KRIEGER, 2004). Formou-se, então, o embrião do que mais tarde viria a ser o Comitê Internacional da Cruz Vermelha (INTERNATIONAL COMMITTEE OF THE RED CROSS, 2020b).

O conjunto dos cinco suíços tinha por ideia central "a promoção do socorro e tratamento aos soldados feridos em combate, sem que fosse esquecida a necessária identificação dos que voluntariamente trabalhariam no amparo aos feridos em campo de batalha, para que não fossem confundidos com combatentes." (SOUSA, 2007, p. 129).

Em outubro de 1863, uma conferência com a presença, basicamente, de países europeus foi convocada para formalizar as propostas do Comitê. Em alusão à bandeira suíça, uma cruz vermelha num fundo branco foi escolhida como símbolo padrão para identificar os profissionais de saúde em campos de batalha. Em 1870 a Turquia adotou uma lua crescente com símbolo, emblema hodiernamente designado como Crescente Vermelho e que substitui a cruz nos países de tradição islâmica (INTERNATIONAL COMMITTEE OF THE RED CROSS, 2020b).

Em 1864, delegados de vários países, incluindo o Brasil, adotaram a primeira Convenção de Genebra que tratava de melhorar a sorte dos militares dos exércitos em campanha, tornando obrigatório que as tropas cuidassem dos soldados feridos, independentemente do lado a que pertencessem. Neste mesmo ano, a Cruz Vermelha teve sua primeira operação de campo na guerra entre Dinamarca e Alemanha, fazendo-se ser vista como um organismo neutro (INTERNATIONAL COMMITTEE OF THE RED CROSS, 2020b). 
Foi durante a Primeira Guerra mundial que o CICV deixou de ser uma pequena instituição para se tornar uma organização internacional. O primeiro passo foi dado com a criação de uma Agência Internacional de Prisioneiros de Guerra (International Prisioners-ofwar Agency), cuja responsabilidade principal era coletar informações dos presos a repassá-las para seus familiares (INTERNATIONAL COMMITTEE OF THE RED CROSS, 2020c).

Um problema enfrentando pelo CICV durante o confronto foi a situação da população civil. Não havia durante aquele período legislação que protegesse os não envolvidos diretamente na condução das atividades bélicas. As normas humanitárias somente salvaguardavam os militares feridos, entretanto, o Comitê não poderia negar o sofrimento dos civis causado por ações dos próprios militares (INTERNATIONAL COMMITTEE OF THE RED CROSS, 2020c).

Como a organização não tinha mandato específico no que concerne às categorias de pessoas ainda não protegidas pelo direito internacional humanitário, o CICV não teve outra escolha senão improvisar, dada a situação de urgência. Isto lançou as bases da política de assistência de civis achados em situação de violência de guerra, uma política que se desenvolveria ao longo dos anos e se tornaria a pedra angular das atividades humanitárias da organização (INTERNATIONAL COMMITTEE OF THE RED CROSS, 2020c, n.p., traduziu-se.)

Durante o conflito, a Cruz Vermelha apontou diversos abusos intencionais perpetrados pelos combatentes e procurou se posicionar em face da brutalidade desnecessária dos beligerantes que usaram novas e potentes armas, até então desconhecidas, como o gás venenoso. No período pós-guerra, o trabalho do CICV também foi intenso, posto que, devido à escala do conflito, o Comitê auxiliou na repatriação de prisioneiros de guerra, bem como ajudou na reconstrução de diversos países devastados pelo confronto (INTERNATIONAL COMMITTEE OF THE RED CROSS, 2020c).

Os anos que se seguiram à Primeira Guerra Mundial e antecederam a Segunda Grande Guerra, isto é, o lapso compreendido entre 1919 e 1939, no sentir do próprio CICV, são anos tidos como um período de consolidação em meio à crise (INTERNATIONAL COMMITTEE OF THE RED CROSS, 2020d).

No turbilhão político, social e econômico que seguiu a guerra, o CICV trabalhou na Europa Central, onde a redução na comida e o tifo estavam afetando uma população já enfraquecida; na Rússia, onde contribuiu para uma enorme operação de assistência internacional para vítimas famintas; na área ocupada de Ruhr; na Silésia Superior, onde seus serviços como um intermediário neutro eram exigidos; e na Grécia e Turquia, onde ajudou pessoas deslocadas pelos conflitos entre os dois países (INTERNATIONAL COMMITTEE OF THE RED CROSS, 2020d, n.p., traduziu-se) 
Ao passo que as atividades do Comitê passaram a alcançar mais pessoas na Europa, deu-se início a um processo de diversificação geográfica fora do continente. Tem-se como exemplo a atuação do CICV na guerra entre Paraguai e Bolívia, assim como no auxílio prestado às vítimas havidas nas lutas chinesas contra o imperialismo japonês.

O que o CICV não podia contar é a Primeira Guerra não seria o último conflito de proporções globais na história do planeta. A população mundial teria de se preparar para outro episódio ainda mais turbulento, cheio de controvérsias, que se transformou, ao cabo, numa mácula na história de atuação do CICV e de seu papel de auxiliador das vítimas nos conflitos armados.

No ano de 1939, com a invasão da Polônia por tropas alemãs, deflagrou-se a Segunda Guerra Mundial. Diferentemente do anterior, o novo conflito foi altamente mecanizado, com bombardeios aéreos tendo por alvo, principalmente, a população civil. Aliás, não só os bombardeios tinham como foco os civis, mas também as várias ocupações brutais que aconteceram por toda batalha (INTERNATIONAL COMMITTEE OF THE RED CROSS, 2020e).

Diante deste cenário, o CICV enfrentou desafios de envergadura. Alguns, conseguiu cumprir satisfatoriamente, outros não. Um ponto de destaque é que nunca dantes o Comitê tinha realizado atividades simultâneas em cinco continentes, o que exigiu recursos humanos e financeiros. A Cruz Vermelha afirma que mais de 50 delegações da organização estavam em funcionamento no período (INTERNATIONAL COMMITTEE OF THE RED CROSS, 2020e). Ademais, as ações do Comitê durante a Segunda Guerra aumentaram sobremaneira.

\begin{abstract}
Além de cumprir com suas atividades tradicionais para com os prisioneiros de guerra, tais como visitar campos ou organizar a agência central de informações acerca dos prisioneiros de guerra (como em 1914-1918) - o CICV também trabalhou arduamente para ajudar os civis a lidar com o desorganizado cotidiano resultante da situação militar. O CICV, então, lançou grandes esforços de apoio ao combate da fome na Grécia e a escassez de alimentos nas Ilhas do Canal (INTERNATIONAL COMMITTEE OF THE RED CROSS, 2020e, n.p., traduziu-se).
\end{abstract}

Enquanto as operações de assistência humanitária foram um sucesso, o mesmo não se pôde dizer de outros pontos de atuação do Comitê. Ainda que tenha tentado ter acesso irrestrito aos prisioneiros de guerra, não conseguiu devido à resistência das potências beligerantes. O CICV logo se viu impossibilitado de ajudar os prisioneiros alemães e soviéticos presos no lado rival (INTERNATIONAL COMMITTEE OF THE RED CROSS, 2020e). 
Outra falha que fere a imagem da organização internacional foi sua ausência junto aos civis nas áreas ocupadas por operações militares ou ao lado dos deportados para campos de morte. No que toca aos campos de concentração, o CICV alega que estava diante de uma cortina impenetrável, conquanto lograsse adentrar eventualmente, atingindo por vezes resultados deficientes, dolorosamente conquistados um por um. "Os críticos falham em entender, ou recusam admitir, quão impotente a Cruz Vermelha era para evitar a existência dos campos de concentração, e que o Comitê Internacional, então chamado de "consciência da humanidade", era incapaz de por um fim neles" (INTERNATIONAL COMMITTEE OF THE RED CROSS, 1973, p.100-101, traduziu-se).

Ainda assim, oficialmente, a organização de origem suíça reitera que sua atividade durante o Holocausto permanece um sinônimo de tragédia na memória da instituição (INTERNATIONAL COMMITTEE OF THE RED CROSS, 2020e). Mas é sempre bom lembrar que a Cruz Vermelha trabalha alicerçada pelos princípios da neutralidade e da não ingerência e que tais, embora tenham sido passíveis de críticas, permitiram, ao longo dos anos, que o trabalho da organização se estendesse por Estados à margem da democracia e dos valores tradicionalmente reconhecidos, por parte das nações ocidentais, por exemplo.

Com o término da Segunda Guerra e a divisão do mundo em dois blocos antagônicos, envolto num intenso clima de ameaça de uma guerra nuclear, o trabalho do CICV estava longe de acabar. Mesmo debaixo de criticismo e de uma situação financeira desfavorável, o CICV conseguiu reunir forças para seguir adiante. Através de uma análise de suas falhas durante o segundo conflito de proporções globais, a organização percebeu que a ausência de normas humanitárias que protegessem as vítimas de conflitos armados era, na verdade, o verdadeiro inimigo a temer, a razão de grande parte do fracasso durante a Segunda Guerra (INTERNATIONAL COMMITTEE OF THE RED CROSS, 2020f).

Desse modo, em agosto de 1949, quatro textos básicos foram adotados em uma conferência diplomática sob os auspícios do Comitê Internacional da Cruz Vermelha. Com as quatro Convenções de Genebra de 1949 nasceu, então, o Direito Internacional Humanitário como hoje o conhecemos. É a partir deste ponto que se tem uma codificação substancial das normas costumeiras do DIH (INTERNATIONAL COMMITTEE OF THE RED CROSS, 2020f).

A Guerra Fria foi um momento de oportunidades para o CICV, posto que justamente nesta época a instituição se firmou no cenário mundial como organismo neutro, intermediando 
em diversas ocasiões o relacionamento conturbado entre o Leste e o Oeste (INTERNATIONAL COMMITTEE OF THE RED CROSS, 2020f).

Nos anos seguintes à edição das Convenções de Genebra, o mundo testemunhou um número alarmante de conflitos internos. A organização não poderia se calar diante da barbárie e em 1977 adotou dois Protocolos Adicionais, sendo o segundo exclusivo para a proteção das vítimas de conflitos armados internos (INTERNATIONAL COMMITTEE OF THE RED CROSS, 2010g).

De inestimável importância, portanto, o papel que o Comitê Internacional da Cruz Vermelha desempenhou na estruturação positiva do Direito Internacional Humanitário e na aplicação das normas humanitárias por conflitos armados ao redor do globo. Um tópico que também merece breve atenção, sem pretender esgotar o assunto, uma vez que escapa a proposta inicial deste trabalho, diz com a questão da natureza jurídica do CICV.

Como pontua Sousa (2007, p. 144), é ponto pacífico que o Comitê seja uma Organização Internacional (OI) enquanto novo ator do Direito Internacional. A polêmica reside, no entanto, na classificação do Comitê dentro dos tipos de OI's existentes. Seria o CICV uma organização não governamental (ONG), uma organização internacional governamental típica ou uma organização diferenciada das demais?

Com a devida ressalva a quem entenda de forma distinta, como Swinarski (2001), o posicionamento oficial defendido pela instituição é que a Cruz Vermelha é um organismo suis generis. Sousa (2007), quando desenvolvendo pesquisa sobre esta questão, questionou a instituição e recebeu como resposta que

O CICV tem uma natureza dupla: enquanto associação privada sujeita ao Código Civil Suíço, é simultaneamente investido de uma funcional personalidade na área de Direito Internacional humanitário. Embora não seja uma organização intergovernamental, nem uma organização não-governamental, no sentido comum do termo. Ao contrário disso, é uma pessoa de direito internacional exercendo funções específicas de caráter de direito internacional que tem sido largamente reconhecida pelos Estados e pelas Nações Unidas e outras organizações internacionais [...] O CICV é usualmente reconhecido como uma organização internacional e goza de personalidade internacional [...] O CICV é uma organização privada que não é composta por Estados. Mas diferentemente de outras organizações que não têm Estados como componentes, o CICV tem personalidade jurídica de direito internacional. Esse fenômeno é único no direito internacional e é a razão pela qual alguns autores classificam o CICV como não sendo nem uma organização intergovernamental nem uma ONG, mas sim uma organização internacional sui generis. (SOUSA, 2007, p. 152, sem negrito no original). 
Deste modo, o CICV é considerado uma organização especial porque tem aspectos tanto de uma organização privada quanto de uma organização intergovernamental, especialmente pelo fato de ser reconhecido pelos demais Estados e pelas Nações Unidas.

Em face de sua história e natureza jurídica, não há como negar a importância e a conexão do Comitê com o Direito Internacional. Assim como o DIH tem princípios balizadores, o CICV é detentor de enunciados subjetivos que orientam sua ação e guiam sua conduta de proteção às vítimas durante as hostilidades. Essa matriz principiológica será adiante estudada.

\section{PRINCÍCPIOS DO CICV E SUA RELAÇÃO COM O DIH}

Os princípios fundamentais do Comitê Internacional da Cruz Vermelha são o resultado de nada menos que um século de experiência acumulada (PICTET, 1979) e estão imbricados com o Direito Internacional Humanitário. Proclamados durante a XX Conferência Internacional da Cruz Vermelha, sediada em Viena, no ano de 1969, eles não só vinculam o trabalho da organização como também diferenciam a instituição dos demais organismos que prestam assistência humanitária (BOUVIER; QUINTIN; SASSÒLI, 2011).

Inicialmente, em 1864, Gustave Moyner, cidadão suíço participante do comitê responsável pelo gérmen de criação do $\mathrm{CICV}$, identificou quatro enunciados que deveriam orientar os passos do grupo: centralização, previdência, neutralidade e solidariedade (DEYRA, 2020).

Por centralização entende-se que deveria existir uma única Sociedade Nacional por Estado $^{4}$, desenvolvendo uma ação que se estendesse por todo o território nacional (DEYRA, 2020). Já por previdência tem-se a ideia de que teria de haver uma preparação para que o Direito Humanitário fosse aplicado igualmente em tempos de paz e não somente enquanto durassem as hostilidades.

Neutralidade, como o próprio nome sugere, é a premissa de que cada Sociedade deveria prestar socorro às vítimas de guerra sem levar em consideração as nacionalidades dos

4“As Sociedades Nacionais são O.N.G.s nacionais cujas actividades variam consoante o país em que se encontrem sediadas e podem consistir na prestação de serviços de saúde e de assistência social ou no desenvolvimento de programas para a juventude. Em tempo de guerra, as Sociedades Nacionais intervêm enquanto auxiliares dos serviços sanitários das forças armadas, tratando dos militares doentes e feridos, ajudando os prisioneiros de guerra, os internados e os refugiados. As Sociedades Nacionais da Cruz Vermelha e do Crescente Vermelho devem ser reconhecidas pelos Estados e respeitar os princípios fundamentais do Movimento para obterem o reconhecimento internacional do C.I.C.V. Depois de preencherem estas condições, as Sociedades Nacionais são agrupadas no seio da Federação Internacional” (DEYRA, 2020, p. 34). 
combatentes. Finalmente, por solidariedade compreende-se que as Sociedades Nacionais estariam comprometidas a prestar assistência humanitária, vinculadas a exercer tal função.

A doutrina é unânime em destacar sete princípios norteadores do CICV, todos erigidos na XX Conferência Internacional Cruz Vermelha acima mencionada. São eles: humanidade, imparcialidade, neutralidade, independência, trabalho voluntário, unidade e universalidade (DEYRA, 2020), (PICTET, 1979), (BOUVIER; QUINTIN; SASSÒLI, 2011). Os princípios são um direcionamento para que o escopo do DIH seja amplo e abarque vítimas da guerra sem distinções.

Deyra (2020) agrupa os sete enunciados em três categorias: substanciais, derivados e orgânicos. O autor considera como integrantes do grupo substancial a humanidade e a imparcialidade. Para ele são substanciais porque não constituem meios para que o serviço humanitário seja posto em prática, sendo em si já um fim almejado pelo CICV e pelo DIH.

O professor francês destaca, ainda, que compõem a esfera dos derivados a neutralidade e a independência. Recebem essa nomenclatura porque, no ponto de vista do pensador, "permitem a transposição dos princípios substanciais para a realidade dos factos" (DEYRA, 2020, p. 37). Os princípios orgânicos, ou ainda organizacionais, referem-se à forma de funcionamento da instituição: serviço voluntário, unidade e universalidade.

Tratando-se dos princípios em espécie, não há como iniciar por outro que não seja o da humanidade, princípio dos princípios no que tange à ação do Comitê (PICTET, 1979). No ver de Bouvier, Quintin e Sassòli (2011, p. 374) a humanidade é notadamente o princípio supremo.

A noção de humanidade dentro do DIH vai além da pena e da caridade, tanto mais porque é da humanidade que todos os demais princípios tiram seu fundamento de validade (DEYRA, 2020). "Se a Cruz Vermelha tivesse um único princípio, seria este [o da humanidade]." (PICTET, 1979, n. p.). Salienta-se que o enunciado da humanidade traz em seu bojo três vertentes: prevenir e aliviar o sofrimento; proteger a vida e a saúde da vítima, e por fim, assegurar o respeito ao indivíduo (DEYRA, 2020), (PICTET, 1979).

A história de ação do CICV mostra que, desde seu início, a preocupação que fez nascer toda a organização foi aliviar o sofrimento daqueles que não mais podem tomar parte das hostilidades e ficavam, portanto, largados à própria sorte, esperando a morte, que seria o único alento capaz de por um fim àquela situação de agonia. Assim é que a ação de fazer diminuir o desespero das pessoas, com um foco reparador, vem acompanhada de uma ação 
preventiva da organização, haja vista que "o melhor meio de lutar contra o sofrimento é impedir que ele surja" (DEYRA, 2020, p. 37).

O segundo elemento que compõe o princípio da humanidade é a proteção da vida e da saúde, tópico tão importante quanto o primeiro, citado acima. A materialização do segundo elo do conceito de humanidade ocorre através das ações de assistência e proteção realizadas pelo Comitê.

No que tange a assegurar a proteção ao indivíduo, não resta dúvida de que este ponto é norteado pelo ideal de respeito pelo ser humano. Não basta assistir e proteger, deve- se, acima de tudo, respeitar. A reflexão aqui é direcionada ao tratamento digno e humano para com os enfraquecidos pela dor da guerra.

Ora, de nada adianta oferecer ajuda colocando-se como sujeito superior, melhor que o necessitado. Tampouco basta tratar a vítima como um ser desvalido. Tratamento humano é mostrar-se preocupado e afetado pela dor do outro, pela só condição de ser humano que ostenta, em igualdade de direitos e deveres.

O próximo princípio trazido à discussão é o da imparcialidade, que engloba três dimensões: não discriminação, proporcionalidade e imparcialidade em sentido estrito. No modo de pensar de Pictet (1979), cada um desses elementos poderia ser considerado um único princípio, se assim a Cruz Vermelha quisesse.

A não discriminação, como anunciado na XX Conferência Internacional da Cruz Vermelha, é a ausência de preconceitos religiosos, étnicos, morais e políticos. Deyra (2020) pontua que na oportunidade em que a Cruz Vermelha estiver prestando assistência humanitária, não há espaço para discriminações subjetivas nem em relação à pessoa que se dispõe a ajudar, muito menos em relação ao beneficiário da atitude altruísta.

Analisando a proporcionalidade, observa-se que o Comitê deve dar prioridade aos casos mais urgentes de sofrimento em detrimento dos menos graves. Nessas situações, e somente nessas, é que um membro da Cruz Vermelha poderá priorizar certos tipos de pessoas sem ferir a não discriminação.

Quando o pessoal médico tiver de lidar com um fluxo massivo de feridos, terão de começar o tratamento por aqueles cujo atraso seria fatal, ou pelo menos prejudicial, lidando posteriormente com aqueles cuja condição não exija intervenção imediata. Da mesma forma, representantes da Cruz Vermelha responsáveis pela distribuição de alimentos ou remédios, deverão ir ao encontro daqueles com necessidades mais urgentes primeiro. (PICTET, 1979, n.p., traduziu-se) 
O histórico das guerras mostra que, infelizmente, é impossível atender a todos os feridos simultaneamente, seja devido à ausência de pessoal, seja devido à insuficiência dos recursos. Portanto, o critério padrão utilizado pela organização é o do sofrimento. "Para sofrimento igual, tratamento igual. Para sofrimento desigual, assistência proporcional à extensão do sofrimento" (PICTET, 1979, n p.).

Imparcialidade em sentido estrito nada mais é que a aplicação de certas regras de forma neutra, sem tomar lados e sem levantar bandeiras ideológicas. Tais regras são traduzidas pelos princípios da humanidade, não discriminação e proporcionalidade, colocados em prática concomitantemente. (PICTET, 1979).

Não é surpresa que a neutralidade seja um dos princípios fundamentais à atuação da instituição pelo mundo todo. Como já estudado, o CICV tem suas origens na Suíça, um país reconhecidamente neutro nas relações internacionais por natureza, fator que gera confiança às partes beligerantes.

Preleciona Haug (1996) que a motivação da neutralidade materializa-se na abstenção de qualquer participação nas hostilidades, bem como em controvérsias de natureza política, racial, religiosa ou ideológica, visando, sempre, ter a confiança de todos. "Somente onde há confiança geral, confiança da população e das autoridades, poderá as instituições do Movimento ter acesso livre às vítimas dos conflitos e desastres e obter o auxílio necessário para sua proteção e atividades de assistência” (HAUG, 1996, n. p., traduziu-se).

A aderência à neutralidade é fator gerador e mantenedor da confiança que os Estados e as demais instituições têm em relação ao trabalho do CICV. O Comitê deve se abster, por conseguinte, de qualquer discussão religiosa, racial ou ideológica para evitar tensões que possam levar ao rompimento da confiança por parte dos entes estatais e demais organismos no cenário internacional. A Cruz Vermelha não deve seguir nenhuma corrente de pensamento, nenhuma doutrina ou filosofia que não seja a sua própria (HAUG, 1996).

Contudo, consoante afirma Haug (1996), em algumas situações a instituição deverá tomar partido de certos problemas e apresentar seu ponto de vista, desde que a temática versada seja prioritariamente humanitária, ainda que envolva outros aspectos secundariamente, como religião ou política. Como exemplo, pode-se mencionar a implementação do Direito Internacional Humanitário em determinada localidade. Caso algum fator esteja atrapalhando a esfera de atuação do CICV, este deve posicionar-se diante da controvérsia porque tem interesse no desenvolvimento das normas humanitárias. 
A neutralidade, somada com o próximo princípio, a independência, permitem que o Comitê tenha mais liberdade em sua atuação. "Se por um lado a neutralidade determina que sejam evitadas intromissões na política, o princípio da independência significa, por outro lado, que a Cruz Vermelha deve proibir qualquer incursão da política na sua esfera privada. Esta independência é não só política, mas também religiosa e económica" (DEYRA, 2020, p. 40).

A Cruz Vermelha tem de ser soberana em suas atitudes, ações e palavras também com o escopo de fomentar a confiança dos demais países. Para que tenha independência, deve firmemente evitar intrusões políticas e ideológicas em seu campo de ação. Não apenas isso. Não deve o CICV ceder em face de pressões de determinados grupos sociais ou fatores econômicos, assim como não deve se associar com nenhuma instituição que não tenha respeito por sua total independência moral e material. O Comitê pode sim cooperar com outras instituições de fundo humanitário, desde que concordem com seu ponto de vista e sua principiologia (PICTET; 1979).

O enunciado seguinte assiste respeito ao serviço voluntário, tido como princípio orgânico da organização internacional. Nos moldes do voluntariado, os membros do Comitê devem ser guiados pelo espírito do altruísmo e não devem visar benefício próprio, mas tão somente a melhoria do mundo. "A Cruz Vermelha deve inspirar-se na dedicação e deve suscitar vocações com vistas a cumprir a sua missão. A dimensão do voluntariado determina que as prestações voluntárias sejam asseguradas por colaboradores não remunerados" (DEYRA, 2020, p. 40-41).

Nos moldes do CICV, um voluntário é alguém que serve não porque foi obrigado, compelido, mas sim por um ato deliberado de compaixão. Entretanto, estabelecendo um cotejo com os voluntários do serviço militar, uma vez que a palavra é dada, não há como voltar atrás e nem tampouco se podem exigir condições de tratamento, porque o trabalho é voluntário (PICTET, 1979).

Deyra (2020) e Pictet (1979) asseveram que o princípio da unidade contém três vertentes. A unidade propriamente dita (ou ainda unicidade), o multidinamismo e a generalidade de ação. Por unicidade, compreende-se que num dado território nacional deve haver apenas uma Sociedade Nacional da Cruz Vermelha com uma liderança centralizada, para evitar que haja comandos confusos e tarefas independentes sem qualquer conexão com os enunciados centrais do Comitê (PICTET, 1979). 
O multidinamismo, por seu turno, está associado à ideia de não discriminação. "A Cruz Vermelha deve ainda estar aberta a todos, independentemente da raça, sexo, religião, opinião ou mesmo da nacionalidade, o que não quer dizer que a Sociedade esteja aberta a qualquer um, já que são exigidas condições de moralidade ou de capacidade para os seus membros" (DEYRA, 2020, p. 41).

Com efeito, a Cruz Vermelha pode recusar candidatos por não preencherem requisitos morais, principalmente para não ferir a neutralidade da instituição perante a sociedade internacional. Pode ainda rejeitar indivíduos que não tenham a habilitação técnica necessária para cargos específicos (médicos, enfermeiros), posto que, embora voluntário, o serviço deve ser prestado com humanidade, obedecendo a padrões de qualidade e prestabilidade.

Um aspecto do multidinamismo e que deve ser ressaltado é que ele colabora com a disseminação da Cruz Vermelha e dos outros princípios da entidade, uma vez que permite a diversos setores sociais estarem representados por diferentes indivíduos. Dessa forma, a membresia não pode ser negada com base em critérios discriminatórios que não tenham justificativa plausível, como as mencionadas anteriormente.

Como último elemento da unidade, tem-se a generalidade de ação. "Como pode haver apenas uma única Sociedade da Cruz Vermelha em um país, é lógico que esta Sociedade deve abarcar dentro de sua esfera de atuação todo o território nacional, pois, caso contrário, haveria falhas em seu trabalho humanitário" (PICTET, 1979, n. p., traduziu-se).

O sétimo e derradeiro princípio é o da universalidade. Nas lições de Pictet (1979) a universalidade tem três ramos: a universalidade em sentido estrito, a igualdade entre as Sociedades Nacionais e a solidariedade. Deyra (2020), diferentemente, disserta apenas acerca da universalidade como um princípio uno e sem subdivisões.

Em Pictet (1979), a universalidade em sentido estrito está atrelada aos princípios da humanidade e não discriminação. Universalidade nada mais é que a vocação universal a qual fora chamado o Comitê: deve estar sempre de braços abertos para todo aquele que requisita seu auxílio e sua assistência. A igualdade entre as Sociedades Nacionais, como o próprio nome indica, sustenta que as Sociedades dos mais diversos Estados soberanos possuem os mesmos direitos e obrigações no bojo do CICV, sendo inadmissíveis preconceitos de qualquer natureza. 
Já por solidariedade, entende-se que malgrado as Sociedades Nacionais sejam dotadas de autonomia, devem ajudar-se mutuamente sempre que necessário por existir um objetivo em comum: à proteção das vítimas.

\section{COMPETENCIAS E FUNÇÕES DO CICV ENQUANTO AGENTE MATERIALIZADOR DO DIH}

As ações do Comitê Internacional da Cruz Vermelha têm mais destaque, obviamente, em tempos de conflitos armados, sobretudo quando tal intervém nas hostilidades com o objetivo de proteger e assistir as vítimas (VIERUCCI, 2001) ${ }^{5}$. Não é por outro motivo que a instituição é considerada promotora e guardiã do Direito Internacional Humanitário (RATNER, 2011).

Contudo, as atividades do CICV não se restringem à assistência humanitária somente. Tendo em mente que a ignorância da lei torna-se um obstáculo à sua implementação, o Comitê Internacional busca a todo custo relembrar os Estados de sua obrigação face às Convenções de Genebra de 1949 e os Protocolos Adicionais de 1977, ficando a cargo de cada um dos que ratificaram as normas internacionais retro citadas tornar as provisões do DIH conhecidas em seu território (INTERNATIONAL COMMITTEE OF THE RED CROSS, 2020a).

Para Bouvier, Quintin e Sassòli (2011) a atuação da organização internacional pode ser dividida em quatro grupos de abordagem: proteção, assistência, cooperação e prevenção.

O caráter protetivo se dá com escopo de preservar a vida, segurança, dignidade e bem estar físico e mental das vítimas de conflitos armados e outras situações de violência. É por meio da abordagem de proteção que o Comitê busca assegurar que as autoridades e outros atores cumpram com suas obrigações e obedeçam aos direitos das vítimas. Da mesma forma, o CICV visa por um fim às violações de qualquer norma concernente ao Direito Internacional Humanitário (BOUVIER; QUINTIN; SASSÒLI, 2011).

No que tange à assistência, seu foco é proteger a vida e restaurar a dignidade de indivíduos ou comunidades afetadas por conflitos armados ou outras situações de violência. Observe-se que para prestar uma assistência efetiva, o Comitê deve procurar suprir as

5 Esclareça-se que, em hipótese alguma, fala-se de intervenção armada ou mesmo que o CICV seja parte nas hostilidades. O Comitê apenas assiste às vítimas do conflito, mantendo sempre sua neutralidade. 
necessidades essenciais deficientes para os indivíduos de acordo com as especificidades culturais e sociais da localidade (BOUVIER; QUINTIN; SASSÒLI, 2011).

Em relação à cooperação, tem-se a relação do Comitê com as Sociedades Nacionais de cada país. Assim, deve a instituição tentar aumentar as capacidades das Sociedades Nacionais, sobretudo em países afetados ou fortemente propensos a seres atingidos por conflitos armados ou outras situações de violência. A cooperação visa, na verdade, otimizar o trabalho tanto do Comitê quanto das Sociedades por meio de ações complementares (BOUVIER; QUINTIN; SASSÒLI, 2011).

Encerram-se as quatro abordagens com a prevenção. O trabalho da organização, nos casos que deve agir com este foco, é de fomentar e promover um ambiente de respeito e dignidade mesmo em locais em que não haja conflitos armados ou outras situações de violência. "Em particular, a abordagem preventiva envolve comunicar, desenvolver, esclarecer e promover a implementação do direito internacional humanitário e outras normas aplicáveis, e promover a aceitação do trabalho do CICV" (BOUVIER; QUINTIN; SASSÒLI, 2011, p. 378).

Há ainda o papel de agente intermediário neutro que tão bem caracteriza as atividades do Comitê. Kraehenbuehl (2008) assevera que como entidade imparcial, neutra e independente, a instituição procura manter diálogo com todos os atores envolvidos numa dada situação de conflito armado ou violência interna, assim como com as pessoas que sofrem as consequências da instabilidade, com o fito de ganhar-lhes respeito e confiança.

Nas palavras do Diretor de Operações do CICV, esta técnica abre espaço para um contato direto tanto com as vítimas quanto com quem põe as hostilidades em prática, além de ajudar na proteção da equipe que presta serviço voluntário à organização. É fazendo uso deste raciocínio que a organização conseguiu proteger pessoas na frente de batalha em áreas de conflito ativo como Colômbia, Afeganistão, Iraque e Somália (KRAEHENBUEHL, 2008); oO Comitê atua também na libertação de reféns:

O CICV pode, por vezes, facilitar a libertação de pessoas privadas de sua liberdade, por exemplo, pessoas capturadas por grupos armados. Somente no último ano, a organização agiu como um intermediário neutro na libertação de civis coreanos capturados no Afeganistão, de chineses presos na Etiópia e Nigéria, e dezenas de civis detidos por grupos armados na Colômbia. Em tais casos todas as partes envolvidas devem consentir com nosso papel [do CICV]. Entretanto, o papel de intermediário neutro não envolve, na verdade, negociar a libertação de reféns ou detidos (KRAEHENBUEHL, 2008, n. p., traduziu-se.) 
Lavoyer (1995) afirma que, para que o Comitê Internacional da Cruz Vermelha cumpra o seu papel de promotor e guardião do Direito Internacional Humanitário, as Convenções de Genebra de 1949 e os Protocolos Adicionais de 1977 conferem à organização certas prerrogativas. Destarte, pode o organismo ter acesso aos prisioneiros de guerra (III Convenção) e aos civis protegidos pela IV Convenção, por exemplo.

As normas humanitárias dão ao Comitê um amplo direito de iniciativa para oferecer seus serviços sempre que considerar que seu status de organização neutra, imparcial e independente pode auxiliar na resolução de conflitos que tenham um fundo humanitário (LAVOYER, 1995).

Ratner (2011) entende que todo o trabalho do CICV pode ser dividido em dois grandes campos de atuação (questões de observância global e intervenções em países específicos), ao passo que Bouvier, Quintin e Sassòli (2011) enxergam quatro esferas de trabalho que serão adiante explanadas.

Em Ratner (2011), para que a instituição internacional de assistência humanitária obtenha sucesso como promotor e guardião das normas do DIH em escala global, o CICV procura influenciar para que os Estados, agentes não estatais e organizações internacionais levem as interpretações do Direito Humanitário mais seriamente. Com esse fim, o organismo internacional age de três maneiras específicas.

Primeiro atua e participa de perto na criação da legislação e documentos humanitários. Malgrado as normas do DIH, que são comandos gerais e abstratos, não sejam criadas para situações específicas, o Comitê Internacional sempre as confecciona com certos Estados e/ou momentos singulares em mente (RATNER, 2011). Não é à toa que, após conflitos de grande escala em que se verificam falhas no âmbito de alcance das leis humanitárias, uma Conferência Internacional da Cruz Vermelha é geralmente convocada para suprir essa lacuna.

Segundo,a organização objetiva atuar como um agente diplomático humanitário multilateral, buscando contato com instituições que desenvolvem trabalhos que também são de interesse do Comitê, tendo em vista adiantar a sua, já lotada, agenda (RATNER, 2011). Em terceiro e último lugar, o CICV busca conscientizar a sociedade mundial acerca da importância do DIH mediante estratégias de comunicação em diversos países (RATNER, 2011).

Nos aspectos concernentes a intervenções em países específicos, para o CICV atuar como promotor e guardião das normas humanitárias, três atitudes são chave. Primeiramente, o 
organismo almeja que os governos estatais ratifiquem os vários tratados do DIH e façam as respectivas alterações em suas legislações domésticas. Quanto mais países ratificarem os tratados humanitários, mais ampla será a ação do Comitê (RATNER, 2011).

Noutro momento, a instituição busca treinar e educar os participantes de conflitos armados por meio de tradução das normas do DIH em doutrina (ainda que o Estado não as tenha ratificado), de políticas operacionais e normas de engajamento, criando uma cultura de respeito pelo Direito Humanitário dentro dos Estados e dos próprios grupos armados (RATNER, 2011).

Finalmente, o CICV, como já exposto, visa manter um constante diálogo com todas as partes envolvidas em um conflito armado que ocorra no interior de um Estado por meio de comunicação direta e confidencial com as partes envolvidas (RATNER, 2011).

Já para Bouvier, Quintin e Sassòli (2011), as atividades da instituição podem ser agrupadas em quatro esferas. A primeira delas é a ajuda de vítimas em situações de conflitos armados, sejam eles internacionais ou internos..

O segundo campo de trabalho do Comitê, na visão dos autores, é representado por outros casos de violência que não tenham atingindo nível de agressividade suficiente para serem considerados conflitos armados, especialmente quando há enfrentamentos dentro de um ente estatal único. Os doutrinadores asseveram, ainda, que quando o CICV presta auxílio em situações que não atingiram o nível adequado de violência para serem classificadas como conflito armado, o faz não por obediência ao Direito Internacional Humanitário, que não abarca tais momentos, mas tão somente em razão do Estatuto do Movimento, que o compele a não ficar inativo diante da dor alheia (BOUVIER; QUINTIN; SASSÒLI, 2011).

A terceira área de atuação do Comitê Internacional, no modo de pensar do trio, resta consubstanciada pelos desastres naturais ou tecnológicos, ou ainda em localidades onde possa ocorrer uma pandemia. Em obediência aos princípios da humanidade e da solidariedade universal, a instituição internacional procurar diminuir e aliviar o sofrimento coletivo nessas situações de instabilidade, especialmente nos períodos mais emergenciais das catástrofes (BOUVIER; QUINTIN; SASSÒLI, 2011).

Por derradeiro, a quarta e última esfera em que o CICV deve atuar, na opinião dos autores, são outras situações eventuais que, embora não sejam fixas e taxativas, podem necessitar da ajuda do Comitê por possuir um caráter humanitário e protetivo (BOUVIER; QUINTIN; SASSÒLI, 2011). 
Não restam dúvidas, portanto, que o organismo internacional está umbilicalmente ligado com o Direito Internacional Humanitário, operando em diversas áreas e locais do mundo em que sua presença tanto necessária quanto essencial.

\section{CONSIDERAÇÕES FINAIS}

O Comitê Internacional da Cruz Vermelha não é apenas uma organização internacional que presta socorro humanitário às vítimas de conflitos armados. Para além disso, o CICV é o principal agente materializador do Direito Internacional Humanitário. Seu surgimento foi responsável pela disseminação do DIH e a principal legislação existente foi realizada sob seu auspício.

Através do $\mathrm{CICV}$ as normas humanitárias foram densamente codificadas e tomaram corpo nas Convenções de Genebra e seus Protocolos Adicionais. Após as Grandes Guerras, o $\mathrm{CICV}$, avaliando as práticas adotadas pelos beligerantes, atuou para que houvesse limites aos novos meios de fazer guerra, a exemplo da proibição e banimento de minas terrestres e estocagem e uso de armas químicas.

A ação do Comitê Internacional da Cruz Vermelha reflete, na prática, os princípios do Direito Internacional Humanitário. Por conta de sua neutralidade, a Cruz Vermelha, mantendo-se equidistante das partes em confronto, consegue prestar socorro e auxiliar indivíduos em situação da vulnerabilidade social que a guerra ocasiona.

Não se pode conceber o Direito Internacional Humanitário hodierno sem mencionar os contributos da Cruz Vermelha. Se hoje há uma série de limitações humanitárias nas conduções de hostilidades foi porque o CICV provocou mudanças no cenário mundial, seja através de seus voluntários socorrendo os necessitados, seja através de suas publicações que difundem o DIH.

Assim é que, diferentemente das demais organizações de cunho humanitário, o Comitê Internacional da Cruz Vermelha atua em várias frentes: no fomento da legislação, na produção acadêmica, no financiamento de atividades humanitárias, na captação e treinamento de voluntário, no fornecimento de medicamentos e demais atividades correlatas. Por esses papéis distintos e relevantes, o Comitê se confunde com o próprio Direito Internacional Humanitário. 


\section{REFERÊNCIAS}

BOUVIER, Antoine A.; QUINTIN, Anne; SASSÒLI, Marco. How does law protect in war? Volume I: outline of International Humanitarian Law. Geneva: International Committee of the Red Cross, 2011.

DEYRA, Michel. Direito Internacional Humanitário. Disponível em:

< http://gddc.ministeriopublico.pt/sites/default/files/documentos/pdf/dih_michel_deyra.pdf > . Acesso: 06.09.2020.

DUNANT, Henry. A memory of Solferino. Geneva: International Committee of the Red Cross, 1986.

HAUG, Hans. Geneva: Neutrality as a Fundamental Principle of the Red Cross.

International Review of the Cross $n^{\circ} 315,1996$.

INTERNATIONAL COMMITTE OF THE RED CROSS. Solferino and the International Committee of the Red Cross. Disponível em: < https://www.icrc.org/en/doc/resources/documents/feature/2010/solferino-feature-240609.htm > Acesso: 07.09.2020

Fouding and earky years of the ICRC (1863-1914). Disponível em:

<http://www.icrc.org/eng/who-we-are/history/founding/overview-section-founding.htm > Acesso: 07.09.2020b

1914-1918: baptism of fire and innovation. Disponível em:

<http://www.icrc.org/eng/who-we-are/history/first-world-war/overview-first-world-war.htm> Acesso: 07.09.2020c

1919-1939: consolidation among crisis. Disponível em: < https://www.icrc.org/en/document/1919-1939-consolidation-among-crises > Acesso 07.09.2020d

1939-1945: descent into hell. Disponível em: < https://www.icrc.org/en/doc/who-weare/history/second-world-war/overview-2-world-war.htm > Acesso: 07.09.2020e

1945-1965: two decades of challenges. Disponível em:

<http://www.icrc.org/eng/who-we-are/history/since-1945/overview-since-1945.htm > Acesso: 07.09.2020f

Treaties, States Parties and Commentaries. Disponível em 
< https://ihl-databases.icrc.org/applic/ihl/ihl.nsf/vwTreatiesByTopics.xsp > Acesso: 07.09.2020g

International Humanitarian Law

- answers to your questions. Geneva: International Committee of the Red Cross, 2015

Inter armas caritas: the work of the International Committee of the Red Cross during the Second World War. Geneva: International Committee of the Red Cross. 2 ed. 1973

KRAEHENBUEHL, Pierre. The neutral intermediary role of the ICRC: at the heart of humanitarian action. Disponível em:<

https://www.icrc.org/en/doc/resources/documents/interview/neutral-intermediary-interview070708.htm\#: :text=The\%20ICRC's\%20role\%20as\%20a,armed\%20conflict $\% 20$ and $\% 20$ inter nal\%20violence.\&text $=$ This $\% 20$ approach $\% 20$ generally $\% 20$ gives $\% 20$ us, the $\% 20$ safety $\% 20$ of $\% 20$ our\%20staff.m > Acesso em: 05.07.2020.

KRIEGER, Cesar Amorim. Direito Internacional Humanitário. Curitiba: Juruá, 2004.

LAVOYER, Jean-Phillipe. Refugees and internally displaced persons: International humanitarian law and the role of the ICRC. Geneva: International Review of the Red Cross. $n^{\circ} 305,1995$

PICTET, Jean. Desarrollo y Principios del Derecho Internacional Humanitario. Geneva: International Committee of the Red Cross, 1982

RATNER, Steven R. Law Promotion Beyond Law Talk: The Red Cross Persuasion, and the Laws of War. European Journal of International Law. v. 22 n. 2, p.459-506, 2001.

SOUSA, Mônica Teresa Costa. Direito Internacional Humanitário. 2. ed. Curitiba: Juruá, 2007.

SWINARSKI, Christophe. Derecho internacional humanitario como sistema de protección de la persona humana en su relación con el derecho internacional de los derechos humano. In: SILVA. Ricardo Mendes; FRAIDENRAIJ, Susana. Elementos de derecho internacional humanitário. México: Universidad Nacional Autónoma, 2001.

VIERUCCI, Luisa. Promoting the teaching of international humanitarian law in universities: the ICRC's experience in Central Asia. Geneva: International Review of the Red Cross. $\mathrm{n}^{\circ}$ $841,2001$. 